\title{
Efeito do manejo florestal da Caatinga no estoque de carbono orgânico em agregados do solo
}

\author{
Effect of Caatinga forest management on organic carbon stock in soil \\ aggregates
}

\author{
Mabel de Oliveira Santos ${ }^{1}$ (D), Patrícia Anjos Bittencourt Barreto-Garcia² (D), \\ Paulo Henrique Marques Monroe ${ }^{2}$ (1), Alessandro de Paula² (i) \\ ${ }^{1}$ Xilolite S.A., Brumado, BA, Brasil \\ ${ }^{2}$ Universidade Estadual do Sudoeste da Bahia - UESB, Vitória da Conquista, BA, Brasil
}

\begin{abstract}
Como citar: Santos, M. O., Barreto-Garcia, P. A. B., Monroe, P. H. M., \& Paula, A. (2021). Efeito do manejo florestal da caatinga no estoque de carbono orgânico em agregados do solo. Scientia Forestalis, 49(129), e3419. https://doi.org/10.18671/scifor.v49n129.16
\end{abstract}

\section{Resumo}

Umas das principais alternativas para a exploração racional dos recursos naturais da Caatinga é o manejo florestal sustentável (MF) o qual pode influenciar diferentes componentes do ecossistema, como a vegetação e o solo. O objetivo deste estudo foi avaliar o efeito de curto prazo de diferentes práticas de manejo florestal sobre a distribuição os estoques de $C$ orgânico total e das classes de agregados do solo em área de Caatinga arbórea, em Contendas do Sincorá (BA). Foram avaliadas três práticas de manejo florestal (corte seletivo por espécie, corte seletivo por diâmetro e corte raso), utilizando como referência a Caatinga não manejada. As amostras de solo foram coletadas na profundidade de $0-10 \mathrm{~cm}$, dois anos após o manejo florestal. As amostras de solo foram fracionadas para obtenção das frações macroagregados, microagregados e silte+argila. As duas primeiras frações foram sonificadas para obter o C ocluso e particulado. Em curto prazo, o manejo florestal promoveu redução dos estoques de C orgânico total do solo, entretanto não ocasionou alterações na distribuição e estoques de C das classes de agregados. Na Caatinga, os macroagregados do solo armazenam mais carbono orgânico que os microagregados e a fração silte+argila.
\end{abstract}

Palavras-chave: Macroagregados; Microagregados; Silte-argila; Indicador físico do solo.

\begin{abstract}
One of the main alternatives for the rational exploitation of the Caatinga biome's natural resources is sustainable forest management (FM) which can influence different components of the ecosystem, such as vegetation and soil. Therefore, the objective of this study was to evaluate the short-term effect of different forest management practices on total organic $C$ stocks and soil aggregate classes in the Caatinga area located in Contendas do Sincorá (BA). Three forest management practices (selectively cutting by species, selectively cutting by diameter and clear cutting) were evaluated, using the unmanaged Caatinga as a control. Soil samples were collected at $0-10 \mathrm{~cm}$ depth after two years of natural regeneration, following the management treatments. Soil samples were fractionated to obtain macroaggregated fractions (2000-250 $\mu \mathrm{m})$, microaggregates $(250-53 \mu \mathrm{m})$ and silt+clay $(<53 \mu \mathrm{m})$. The first two fractions were sonicated to obtain the occluded and particulate carbon. In the short-term, forest management promoted reduction of total organic $\mathrm{C}$ stocks, but did not cause changes in the distribution and $\mathrm{C}$ stocks of the aggregate classes.
\end{abstract}

Keywords: Macroaggregates; Microaggregates; Silt-clay; Soil physical indicator.

Fonte de financiamento: Conselho Nacional de Desenvolvimento Científico e Tecnológico (CNPq), processo 484260/2013-8.

Conflito de interesse: Nada a declarar.

Autor correspondente: patriciabarreto@uesb.edu.br

Recebido: 1 julho 2019.

Aceito: 29 maio 2020

Editor: Paulo Henrique Müller Silva.

(c) (i) Este é um artigo publicado em acesso aberto (Open Access) sob a licença Creative Commons Attribution, que permite uso, distribuição e reprodução em qualquer meio, sem restrições desde que o trabalho original seja corretamente citado. 


\section{INTRODUÇÃO}

O bioma Caatinga é uma formação vegetal exclusivamente brasileira, que está localizada na região semiárida do país e abrange os estados do Ceará, Rio Grande do Norte, Piauí, Paraíba, Pernambuco, Alagoas, Sergipe, Bahia e Minas Gerais (Brasil, 2014). Apesar da sua importância, a Caatinga ainda é o bioma menos favorecido de proteção no Brasil e vem sendo intensamente impactado por interferências antrópicas. Dentre as principais causas destas interferências, destaca-se a remoção indiscriminada da vegetação, que ocasiona a redução do estoque de biomassa vegetal e, consequentemente, da cobertura dos solos (Virgens et al., 2017).

Uma das alternativas que se apresentam para o uso racional dos recursos da Caatinga é o manejo florestal sustentável (MF). No Brasil, o MF em áreas de vegetação nativa é regulamentado pela lei federal $n^{\circ} 12.651$ de 25 de maio de 2012 (Brasil, 2012), que o define como um conjunto de intervenções realizadas em uma floresta, com objetivo de obter produtos e serviços sem comprometer a sua capacidade produtiva e diversidade biológica.

No entanto, as atividades de manejo florestal, mesmo que realizadas com observância de critérios técnicos, podem causar efeitos adversos no ecossistema (Souza \& Soares, 2013). A magnitude destas alterações depende da prática de corte adotada, que pode influenciar a regeneração natural, biodiversidade e os ciclos de carbono e nutrientes. Segundo a Empresa Brasileira de Pesquisa Agropecuária (2007), as principais práticas de manejo florestal adotadas na Caatinga são o corte raso e o corte seletivo por diâmetro mínimo ou por espécie. Apesar disso, pouco se sabe sobre quais seriam os manejos mais adequados à conservação das características do bioma.

Para identificar o nível de interferência ocasionado por diferentes práticas de manejo, é necessário compreender as interações entre os componentes do ecossistema, acima e abaixo do solo. Diversas propriedades mensuráveis do solo podem ser utilizadas como indicadores capazes de refletir impactos em sua qualidade (Andrews et al., 2004) e na condição de sustentabilidade de um determinado ecossistema (Araújo \& Monteiro, 2007).

Dentre os principais indicadores físicos do solo estão a densidade, porosidade, capacidade de retenção de água e estabilidade de agregados. A agregação do solo possibilita a formação de estruturas de diferentes formas e tamanhos, denominadas de macro ou microagregados, que resultam da ligação entre as partículas minerais e a matéria orgânica do solo (MOS), na presença das cargas elétricas dos colóides, de agentes cimentantes e da ação microbiana do solo (Tisdall \& Oades, 1982). Por essa razão, a agregação do solo está diretamente relacionada com outros atributos edáficos, com destaque para o carbono orgânico do solo (COS).

Sendo assim, a adoção de diferentes práticas de manejo pode influenciar de forma direta ou indireta a agregação e, consequentemente, o armazenamento de carbono orgânico no solo. Nessa condição, a quantificação do COS tem sido frequentemente empregada na avaliação da sustentabilidade de sistemas florestais e agrícolas. Além dos estoques totais de COS, tem sido adotado o estudo da sua distribuição em classes de agregados, que representam compartimentos da MOS e expressam diferenças no tempo de permanência do C no solo (Costa Júnior et al., 2011). De acordo com Feller \& Beare (1997), o tempo de permanência do COS no interior dos agregados (em relação à matéria orgânica livre) é maior nos microagregados do que nos macroagregados, devido a sua maior proteção física.

Mudanças na vegetação, especialmente nos fatores relacionados à dinâmica florestal, podem afetar significativamente as entradas de matéria orgânica no solo via deposição da serapilheira. A remoção da vegetação, por exemplo, pode reduzir a cobertura do solo e o acúmulo de carbono orgânico, influenciando o ciclo de formação dos agregados. Sendo assim, o conhecimento da distribuição do COS em classes de agregados do solo pode permitir avaliar mudanças na dinâmica dos compartimentos da MOS e auxiliar na identificação do manejo florestal mais adequado à manutenção das características do solo.

Diante do exposto, este trabalho objetivou avaliar o efeito à curto prazo de diferentes práticas de manejo florestal sobre os estoques de carbono orgânico total e das classes de agregados do solo em área de Caatinga arbórea. 


\section{MATERIAL E MÉTODOS}

\section{Caracterização da área}

O estudo foi conduzido na Floresta Nacional Contendas do Sincorá (FLONA), em área de Caatinga arbórea, classificada como Savana-Estépica Florestada (Instituto Brasileiro de Geografia e Estatística, 2012), onde são frequentes as espécies Myracrodruon urundeuva (Engl.) Fr. All., Schinopsis brasiliensis (Engl.), Tabebuia sp., Aspidosperma pyrifolium (Mart.) e Cereus jamacarus Mill (Lima \& Lima, 1998). A área está localizada no município de Contendas do Sincorá, na Chapada Diamantina, região sudoeste da Bahia, Brasil. O clima da região é semiárido quente (BSwh), conforme classificação de Köppen.

A FLONA foi criada em 1999, após longo histórico de exploração madeireira para a produção de carvão vegetal, e tem como objetivo principal o uso múltiplo sustentável dos recursos florestais e a pesquisa científica, com ênfase em métodos para exploração sustentável de floretas nativas (Brasil, 2006), incluindo-se assim o manejo florestal. A escolha da área mais apropriada para a instalação do experimento ocorreu de acordo com os critérios estabelecidos pela Rede de Manejo Florestal da Caatinga.

A área experimental é constituída por quatro tratamentos, que correspondem a uma condição de Caatinga não manejada e três tipos de manejo florestal. Assim, foram adotados quatro tratamentos: (a) Caatinga nativa - Caatinga não manejada, sem interferência antrópica; (b) corte seletivo por espécie (Cesp) - derrubada de árvores de três espécies de maior ocorrência na área (Commiphora leptophloeos (Mart.) J. B. Gillett, Jatropha molissima (Pohl) Baill e Pseudobombax simplicifolium A. Robyns); (c) corte seletivo por diâmetro mínimo (Cdap) derrubada de todas as árvores com diâmetro à altura do peito (dap - 1,30 m a partir do nível do solo) maior ou igual a $5 \mathrm{~cm}$; e (d) corte raso (Craso) - corte de $100 \%$ das árvores e arbustos, independentemente do tamanho, espécie e dap. Na área experimental, foram demarcadas quatro unidades amostrais de $20 \times 20 \mathrm{~m}\left(400 \mathrm{~m}^{2}\right)$ para cada tratamento, totalizando 16 unidades amostrais, que foram distribuídas de forma aleatória e espaçadas entre si em aproximadamente $1 \mathrm{~m}$. O manejo florestal foi realizado em maio de 2015, com a retirada de todo material lenhoso e manutenção dos resíduos de colheita (galhos finos, folhas e cascas) nas áreas manejadas. Antes do manejo, a área estudada encontrava-se em estágio sucessional tardio, tendo em vista que não sofria intervenção antrópica desde 1997 (ano do último registro de exploração) (Brasil, 2006).

O solo da área estudada é classificado como Argissolo Vermelho-Amarelo (Brasil, 2006) e apresenta características químicas e granulométricas (profundidade 0-10 cm) conforme Tabela 1. As análises para esta caracterização foram realizadas empregando-se os procedimentos descritos por Empresa Brasileira de Pesquisa Agropecuária (2017): granulometria pelo método da pipeta e atributos químicos ( $\mathrm{pH}$ em água; $\mathrm{P}$ e K por Mehlich; $\mathrm{Ca}^{+2}, \mathrm{Mg}^{+2}$ e Al+3 trocáveis por $\mathrm{KCl} 1 \mathrm{~mol} \mathrm{~L}^{-1}$ ).

Tabela 1. Características químicas e a granulométricas de solo (profundidade 0-10 cm) sob Caatinga não manejada (Caatinga nativa) e Caatinga submetida a manejo florestal (Cesp - corte seletivo por espécie; Cdap - corte seletivo por diâmetro e CR - corte raso)

\begin{tabular}{|c|c|c|c|c|c|c|c|c|c|}
\hline \multirow{2}{*}{ Tratamentos } & \multirow{2}{*}{$\mathrm{pH}$} & \multirow{2}{*}{$\frac{P}{\mathrm{mg} \mathrm{dm^{-3 }}}$} & $\mathbf{K}$ & $\mathrm{Ca}$ & Mg & $\mathrm{H}+\mathrm{AL}$ & Areia & Silte & Arg \\
\hline & & & \multicolumn{4}{|c|}{--- $\mathrm{cmol}_{\mathrm{c}} \mathrm{dm}^{3}$} & \multicolumn{3}{|c|}{ 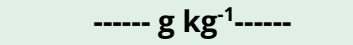 } \\
\hline Caatinga nativa & 6,6 & 4 & 0,2 & 4,8 & 1,9 & 1,7 & 190 & 430 & 380 \\
\hline Cesp & 6,4 & 3 & 0,2 & 4,1 & 1,7 & 2,0 & 210 & 370 & 420 \\
\hline Cdap & 6,5 & 3 & 0,2 & 3,8 & 1,8 & 2,0 & 180 & 410 & 410 \\
\hline Craso & 6,3 & 3 & 0,2 & 3,8 & 1,7 & 1,9 & 200 & 360 & 440 \\
\hline
\end{tabular}

Em que: $\mathrm{pH}=$ ph em água; $\mathrm{P}=$ Fósforo; $\mathrm{K}=$ Potássio; $\mathrm{Ca}=$ Cálcio; $\mathrm{Mg}=$ Magnésio; $\mathrm{H}+\mathrm{Al}=$ acidez trocável (hidrogênio + alumínio). 


\section{Coleta e preparo das amostras de solo}

As coletas de solo foram realizadas em julho de 2017, quando as áreas manejadas encontravam-se com dois anos de regeneração natural. Em cada parcela experimental, foram coletadas aleatoriamente cinco amostras simples de solo (profundidade 0-10 cm) com auxílio de trado holandês, que foram reunidas para obter uma amostra composta. Além das amostras deformadas, foram coletadas amostras indeformadas na mesma profundidade, com uso de anel volumétrico.

As amostras deformadas de solo foram secas ao ar e, em seguida, passadas por uma peneira de $2.000 \mu \mathrm{m}$ (Terra Fina Seca ao Ar - TFSA). As amostras indeformadas foram utilizadas para determinação da densidade do solo, que consistiu em secar as amostras de solo $\left(105^{\circ} \mathrm{C}\right)$ até peso constante para obtenção da massa seca e relacionar com o volume conhecido do anel volumétrico.

\section{Fracionamento em classes de agregados}

Para o fracionamento do solo, foi adotada a técnica do peneiramento úmido, conforme empregado por Gama-Rodrigues et al. (2010) e Monroe et al. (2016), que consistiu na utilização de uma sequência de peneiras com diferentes aberturas para separação do solo em classes de agregados de diferentes tamanhos. Para isso, utilizou-se subamostras de $50 \mathrm{~g}$ de solo (TFSA), que foram submersas em um Becker de $250 \mathrm{ml}$ com água destilada por cinco minutos. Após isso, as amostras foram passadas em peneira de $250 \mu \mathrm{m}$, com movimentos repetitivos de cima para baixo (aproximadamente $3 \mathrm{~cm}$ ), durante quatro minutos.

A fração que restou no topo da peneira de $2000-250 \mu \mathrm{m}$ foi coletada em um recipiente de plástico de $400 \mathrm{ml}$ e denominada macroagregados (2000-250 $\mu \mathrm{m})$. Posteriormente, as amostras que passaram pela peneira de $250 \mu \mathrm{m}$ foram tamisadas novamente em peneira de $53 \mu \mathrm{m}$, repetindo-se o mesmo processo no qual foi obtida a fração de macroagregados. A fração retida na peneira de $53 \mu \mathrm{m}$ foi denominada microagregados $(250-53 \mu \mathrm{m})$. Por fim, as amostras que passaram na peneira de $53 \mu \mathrm{m}$ foram denominadas fração silte-argila ( $<53 \mu \mathrm{m}$ ).

Todas as frações foram secas em estufas a $60^{\circ} \mathrm{C}$ por 72 horas. Após isso, foram pesadas em balança analítica de precisão $(0,0001 \mathrm{~g})$ e calculando-se a percentagem do peso de cada fração. A eficiência de recuperação das massas dos agregados, obtida pela soma das massas das três classes (macro, micro e silte-argila) em função da massa das amostras de solo antes do peneiramento, foi sempre superior a $98 \%$.

\section{Sonificação das classes dos agregados}

Com propósito de promover o rompimento dos agregados do solo e quantificar o carbono ocluso nos agregados, foi adotada a técnica de sonificação, como utilizado por GamaRodrigues et al. (2010).

Para este procedimento, pesou-se $5 \mathrm{~g}$ da fração de maior diâmetro (macroagregado entre 2000-250 $\mu \mathrm{m}$ ) ou $3 \mathrm{~g}$ da fração de diâmetro menor (microagregado - 250-53 $\mu \mathrm{m}$ ). Em seguida, as amostras foram submersas em $100 \mathrm{ml}$ de água deionizada em Becker de $500 \mathrm{ml}$. Após isso, foi inserida uma sonda na profundidade de $10 \mathrm{~mm}$, mantendo-se a temperatura da solução abaixo de $35^{\circ} \mathrm{C}$ com o uso de bolsas de gelo.

As amostras foram sonificadas utilizando processador ultra-sônico - Cole Parmer 60 e energia aplicada (EA) obtida na calibração com uso de uma amplitude de 38\% durante 10 minutos.

As amostras sonificadas passaram novamente pelas peneiras em que foram obtidas as classes de macroagregados (entre $2000-250 \mu \mathrm{m}$ ) e microagregados (250-53 $\mu \mathrm{m}$ ). O carbono orgânico do material que passou pela peneira de macroagregados e microagregados foi chamado de carbono ocluso e o carbono orgânico do material que ficou retido na peneira foi chamado de carbono orgânico particulado (Gama-Rodrigues et al., 2010). 


\section{Teores e estoques de $\mathrm{C}$ orgânico}

Os teores de $\mathrm{C}$ orgânico do solo (COS) e das frações foram determinados via oxidação com $\mathrm{K}_{2} \mathrm{Cr}_{2} \mathrm{O}_{7}$ 0,167 mol L-1 em meio ácido (Yeomans \& Bremner, 1988). A partir dos teores e da densidade do solo, foram calculados os estoques de $C$ do solo na profundidade $0-10 \mathrm{~cm}$, conforme a Equação 1.

$\mathrm{COS}=\mathrm{COS}_{\mathrm{t}} \times \mathrm{DS} \times \mathrm{ECS}$

Em que: $\mathrm{COS}=$ estoque de carbono do solo $\left(\mathrm{Mg} \mathrm{ha}^{-1}\right), \mathrm{COS}_{\mathrm{t}}=$ teor de carbono orgânico do solo (g $\left.100 \mathrm{~g}^{-1}\right), \mathrm{DS}=$ densidade do solo $\left(\mathrm{g} \mathrm{cm}^{-3}\right)$ e ECS = espessura da camada de solo $(\mathrm{cm})$.

Os estoques de carbono orgânico ocluso e particulado nos agregados foram calculados de acordo com a Equação 2.

$\mathrm{COC}$ ou $\mathrm{COP}=\% \operatorname{COS} \times \% \mathrm{MA} \times \mathrm{DS} \times \mathrm{ECS}$

Em que: $\mathrm{COC}=$ estoque de carbono orgânico ocluso $\left(\mathrm{Mg} \mathrm{ha}^{-1}\right), \mathrm{COP}=$ estoque de carbono orgânico particulado $\left(\mathrm{Mg} \mathrm{ha}^{-1}\right), \mathrm{COS}=$ teor de carbono orgânico do agregado, $\mathrm{MA}=$ massa do agregado, DS é a densidade do solo $\left(\mathrm{g} \mathrm{cm}^{-3}\right)$ e ECS = espessura da camada de solo $(\mathrm{cm})$.

Os estoques de COS, COC e COP foram corrigidos de acordo com a espessura da camada de solo, de $10 \mathrm{~cm}$, conforme proposto por Ellert \& Bettany (1995), que consideram que a espessura da camada de solo pode sofrer compactação pelo manejo adotado quando sistemas naturais são convertidos. Para isso, considerou-se a espessura da camada de solo do tratamento de referência (Caatinga não manejada) e, para calcular a espessura da camada de solo a ser corrigida, utilizou-se a Equação 3.

$\mathrm{ECS}_{\text {correção }}=((\mathrm{MR}-\mathrm{MT}) / \mathrm{DS}) / 100$

Em que: $\mathrm{ECS}_{\text {correção }}$ = espessura da camada a ser adicionada ou subtraída para correção do estoque $(\mathrm{cm}), \mathrm{MR}=$ massa de solo na camada $0-10 \mathrm{~cm}$ do tratamento de referência $\left(\mathrm{Mg} \mathrm{ha}^{-1}\right)$, $\mathrm{MT}=$ massa de solo na camada 0-10 $\mathrm{cm}$ do tratamento manejado $\left(\mathrm{Mg} \mathrm{ha}^{-1}\right)$ e $\mathrm{DS}=$ densidade do solo $\left(\mathrm{g} \mathrm{cm}^{-3}\right)$.

\section{Taxa de perda de carbono}

Para estimar a taxa de perda de carbono do solo (TPC) com o manejo florestal da Caatinga, foi empregada a Equação 4.

$\mathrm{TPC}=\left(\operatorname{COS}_{\mathrm{R}}-\mathrm{COS}_{\mathrm{MF}}\right) / \mathrm{T}$

Em que: TPC = taxa de perda do carbono orgânico, $\operatorname{COS}_{R}=$ carbono orgânico do solo do tratamento de referência $\left(\mathrm{Mg} \mathrm{ha}^{-1}\right)$ (Caatinga nativa), $\mathrm{COS}_{\mathrm{MF}}=$ carbono orgânico do tratamento manejado $\left(\mathrm{Mg} \mathrm{ha}^{-1}\right)$ e $\mathrm{T}$ = período após o manejo em anos.

\section{Análise Estatística}

Os dados foram submetidos aos testes de Cochran (homocedasticidade) e de Lilliefors (normalidade dos dados) para as pressuposições da análise de variância. Com os dados paramétricos, foram realizadas comparações múltiplas das médias dos tratamentos pelo teste de Fisher a 95\% de significância. Foram utilizados os Softwares Statistica $\otimes_{V}$.10.0 e Sigmaplot ${ }^{\circledR}$ v.12.0 para realização das análises estatísticas e construção dos gráficos. 


\section{RESULTADOS E DISCUSSÃO}

\section{Carbono orgânico total}

Observou-se redução dos estoques de $\cos$ nos tratamentos manejados, que apresentaram média de 31,7 Mg ha-1, em relação a Caatinga nativa (64,6 $\mathrm{Mg} \mathrm{ha}^{-1}$ ) (Figura 1). Este resultado pode ser atribuído à alteração das características iniciais de equilíbrio dinâmico do ecossistema, independente da prática de manejo florestal adotada, que estaria ocasionando o desbalanceamento dos fatores que determinam a formação da matéria orgânica e aqueles que promovem a sua decomposição. Além disso, características típicas do bioma Caatinga, como baixa pluviosidade anual, altas temperaturas e condições de solo pouco intemperizados, podem ter favorecido esta redução, uma vez que promovem a diminuição da produção primária e aceleração da decomposição da matéria orgânica do solo (MOS) (Maia et al., 2008).

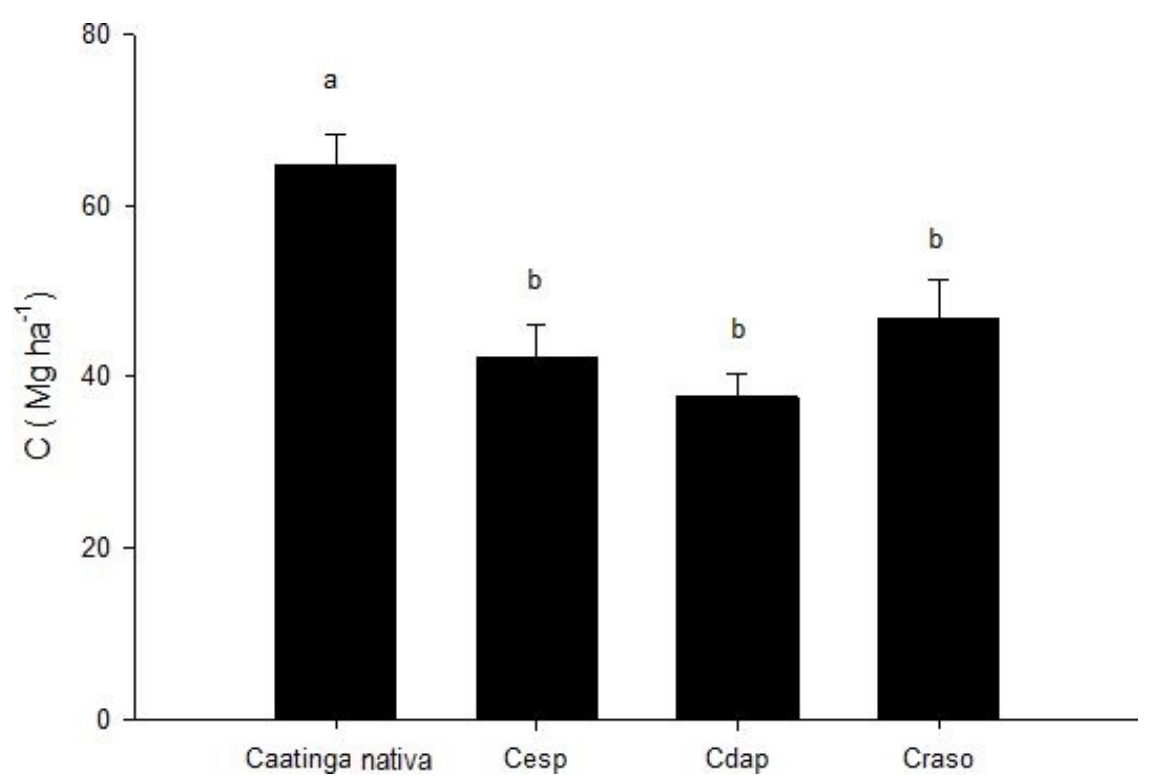

Figura 1. Estoques de carbono orgânico total de solo (profundidade 0-10 cm) sob Caatinga não manejada (Caatinga nativa) e Caatinga submetida a manejo florestal (Cesp - corte seletivo por espécie; Cdap - corte seletivo por diâmetro e CR - corte raso). Letras minúsculas iguais não diferem entre si pelo teste de Fisher a 5\% de significância.

A TPC representou 13,5 Mg ha-1 ano-1 no corte seletivo por diâmetro (Cdap), 11,1 $\mathrm{Mg} \mathrm{ha}^{-1}$ ano-1 no corte seletivo por espécie (Cesp) e 8,9 $\mathrm{Mg} \mathrm{ha}^{-1}$ ano $^{-1}$ no corte raso (Craso). A menor TPC do corte mais invasivo deve estar relacionada à grande quantidade de resíduos vegetais deixados nas áreas após o manejo, conforme constatado por Batista et al. (2018), tendo em vista que a matéria orgânica é responsável pelo aporte de C orgânico no solo. Por sua vez, os maiores valores de TPC nos tratamentos Cesp e Cdap podem ser resultantes de mudanças no aporte anual de resíduos vegetais, na taxa de decomposição da matéria orgânica e ainda em características físicas do solo (Calonego et al., 2012).

Reduções no COS também foram verificadas por Araújo et al. (2013), que observaram diminuição de $41 \%$ ao comparar áreas de floresta submetida a manejo florestal com floresta não manejada. Estes autores atribuíram o resultado às menores entradas de materiais orgânicos, aumento da erosão do solo e aceleração dos processos de mineralização da MOS e oxidação de carbono orgânico na floresta manejada. A presença da floresta inalterada estaria favorecendo o aumento ou manutenção do estoque de COS. 


\section{Classes de agregados}

Os tratamentos manejados e Caatinga nativa não apresentaram diferenças significativas em relação as classes de agregados (macroagregados e microagregados) e a fração silte+argila (Figura 2). Isso demonstra que as interferências na vegetação não promoveram alterações na estrutura do solo, preservando a condição inicial do ecossistema, possivelmente por ter sido adotado sistema de colheita semi-mecanizado (com uso de motosserra e sem tráfego de máquinas). O manejo florestal não provocou alterações diretas às características físicas do solo, mantendo a estrutura semelhante à da Caatinga não manejada. Manejos mais invasivos podem ocasionar aumentos na compactação e erosão do solo, bem como, alterações na taxa de decomposição e quantidade de matéria orgânica fornecida pela vegetação, o que provoca modificações no tamanho dos agregados, porosidade e densidade do solo (Medeiros et al., 2018).

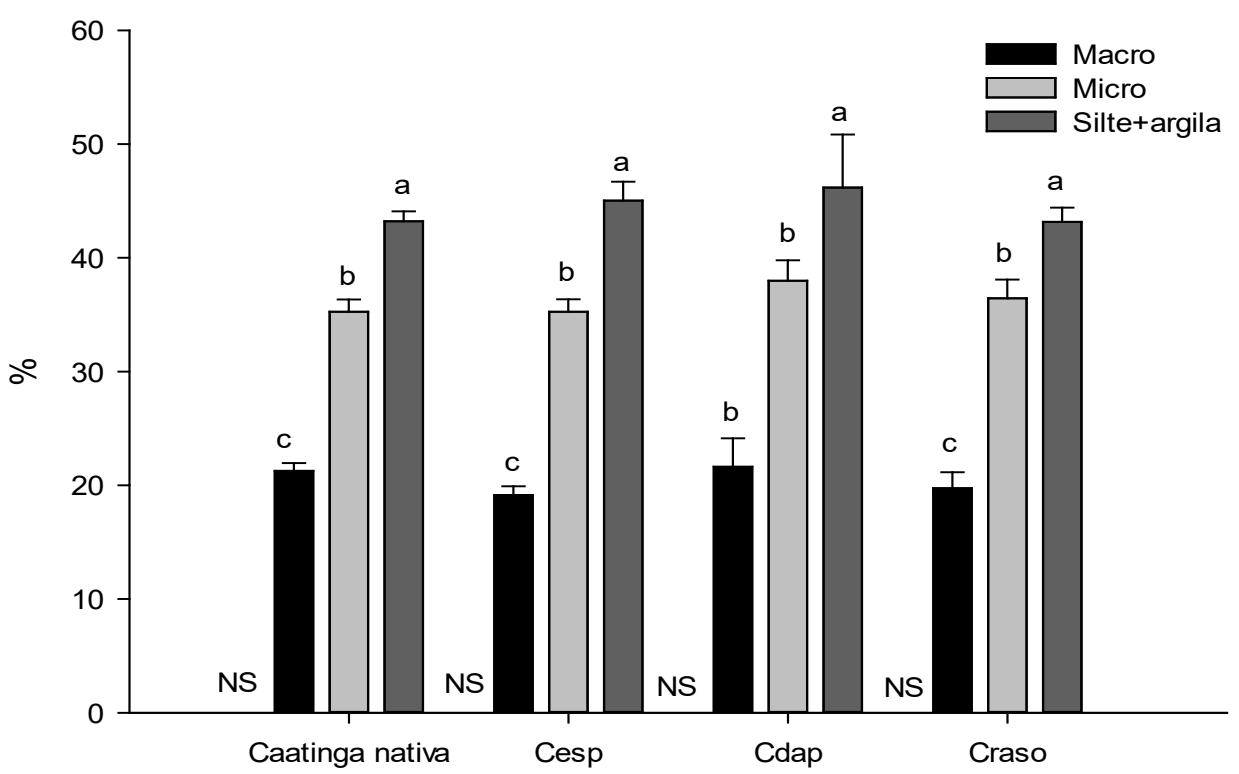

Figura 2. Porcentagem das classes de agregados de solo (profundidade 0-10 cm) sob Caatinga não manejada (Caatinga nativa) e Caatinga submetida a manejo florestal (Cesp - corte seletivo por espécie;

Cdap - corte seletivo por diâmetro e CR - corte raso). Letras minúsculas iguais que compararam as classes dos agregados dentro de cada tratamento, não diferem entre si pelo teste de Fisher a 5\% de significância.

Em todos os tratamentos houve predominância da fração silte + argila, que representou, em média, 44,4\%. Após essa fração, observou-se maior participação dos microagregados (média de 36,2\%) seguida dos macroagregados (média de 20,4\%), embora sem variação entre estas frações no manejo Cdap. A prevalência da fração silte+argila deve ter íntima relação com a granulometria do solo estudado, que apresenta maior abundância de partículas de silte e argila e menor de areia (Tabela 1).

Maiores quantidades da fração silte+argila indicam dispersão das partículas minerais do solo, que não estão ligadas entre si por agentes cimentantes originários da MOS para compor agregados de maior tamanho. Isso pode estar relacionado a acelerada decomposição da MOS no ambiente de baixa produção de serapilheira dada às características do bioma Caatinga, conforme citado anteriormente. A estabilização dos agregados na camada superficial do solo depende do teor de matéria orgânica e da ação dos ciclos sucessivos de secagem e umedecimento do solo (Vasconcelos et al., 2010). 


\section{Carbono das classes de agregados}

Embora a implementação do manejo florestal tenha ocasionado redução dos estoques de $\operatorname{COS}$ (Figura 1), não foi observado efeito significativo dos tratamentos nos estoques de carbono (C) orgânico das diferentes classes de agregados e fração silte+argila (Figura 3). Esta ausência de variação pode estar relacionada ao fato deste estudo ter sido realizado em curto espaço de tempo após o manejo florestal (apenas dois anos), que não teria sido suficiente para expressar diferenças nas quantidades de $C$ orgânico dos agregados. De acordo com Conen et al. (2004), a mensuração de mudanças no carbono do solo é difícil uma vez que seu acúmulo no solo é um processo lento e sua variabilidade espacial é alta.

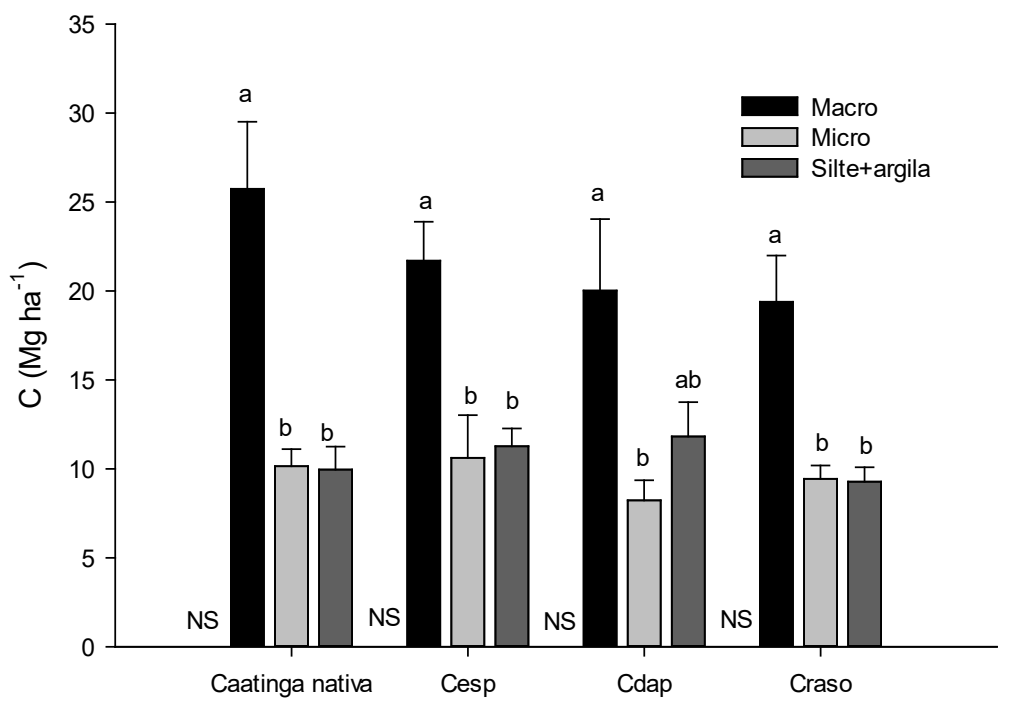

Figura 3. Estoques de carbono orgânico nas classes de agregados de solo (profundidade 0-10 cm) sob Caatinga não manejada (Caatinga nativa) e Caatinga submetida a manejo florestal (Cesp - corte seletivo por espécie; Cdap - corte seletivo por diâmetro e CR - corte raso). Letras minúsculas iguais que compararam as classes dos agregados dentro de cada tratamento, não diferem entre si pelo teste de Fisher a 5\% de significância.

De forma geral, o estoque de C orgânico foi superior nos macroagregados em relação aos microagregados e a fração silte+argila, que não diferiram entre si. A única exceção foi observada no Cdap, que não mostrou variação entre o $C$ dos macroagregados e da fração silte+argila.

Considerando o conjunto dos tratamentos, o C orgânico estocado nas classes de agregados representou, em média, 22, 10 e $11 \mathrm{Mg} \mathrm{ha}^{-1}$ para macroagregados, microagregados e silte+argila, respectivamente. A maior participação dos macroagregados na distribuição do COS, apesar do solo estudado apresentar predominância da fração silte+argila (Figura 2), pode ser explicada pela presença de matéria orgânica e agentes cimentantes temporários (como hifas de fungos, raízes finas, actinomicetos), fundamentais no processo de formação dos macroagregados (Tisdall \& Oades, 1982), o que estaria elevando a sua concentração de carbono. Resultados semelhantes foram encontrados por Costa Júnior et al. (2011), que observaram maiores estoques de carbono orgânico nos macroagregados $\left(39,9 \mathrm{~g} \mathrm{~kg}^{-1}\right) \mathrm{e}$ menores nos microagregados $\left(25,1 \mathrm{~g} \mathrm{~kg}^{-1}\right)$ em solo sob vegetação nativa de Cerradão. De acordo com Ferreira et al. (2007), se por um lado o C aumenta a estabilidade dos agregados, por outro, os agregados, em especial os macroagregados, diminuem a taxa de decomposição da matéria orgânica em virtude da proteção física, fazendo com que o C nos agregados esteja mais diretamente correlacionado com os teores de COS do solo. 


\section{Carbono ocluso e particulado}

Nos macroagregados, os estoques de $\mathrm{C}$ ocluso (interior dos agregados) e $\mathrm{C}$ particulado (carbono livre) não variaram entre os tratamentos. Em todos os tratamentos, foram encontradas maiores quantidades de carbono na fração particulada (média de $2,1 \mathrm{Mg} \mathrm{ha}^{-1}$ ) em relação a fração oclusa (média de $1,0 \mathrm{Mg} \mathrm{ha}^{-1}$ ) (Figura 4a).
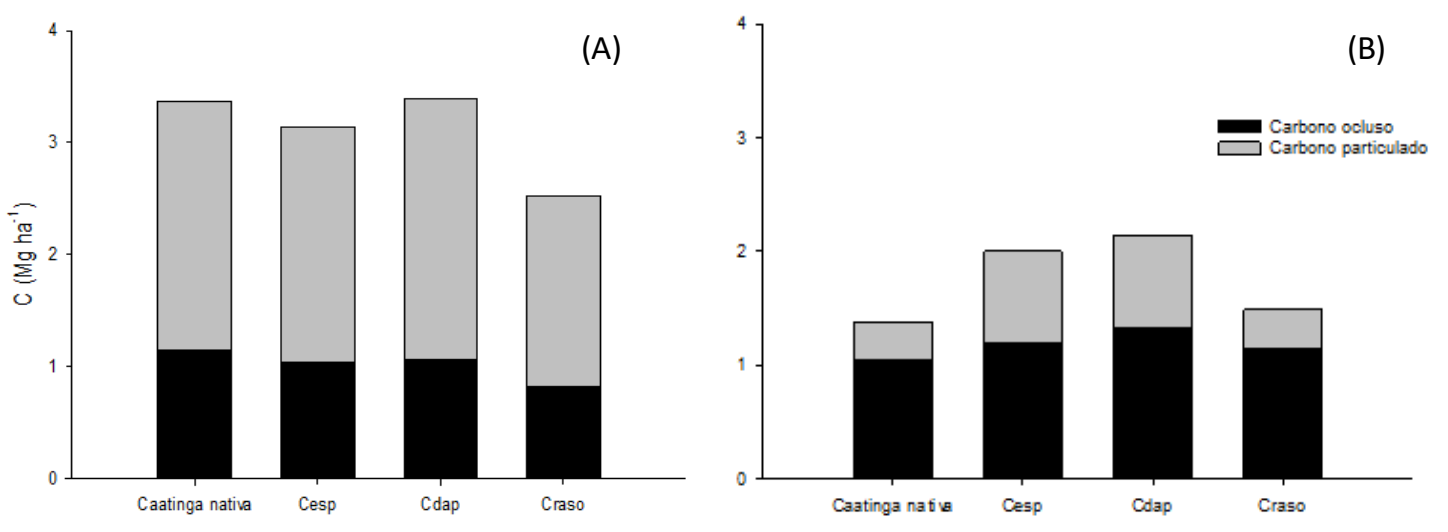

Figura 4. Estoques de carbono orgânico ocluso e particulado dentro dos macroagregados (a) e dos microagregados (b) de solo (profundidade 0-10 cm) sob Caatinga não manejada (Caatinga nativa) e Caatinga submetida a manejo florestal (Cesp - corte seletivo por espécie; Cdap - corte seletivo por diâmetro e CR - corte raso).

Nos microagregados, maiores estoques $\mathrm{C}$ foram observados na fração oclusa (média de $\left.1,2 \mathrm{Mg} \mathrm{ha}^{-1}\right)$, que representou o dobro do $\mathrm{C}$ da fração particulada (Figura $4 \mathrm{~b}$ ). Apenas para o $\mathrm{C}$ particulado houve variação entre tratamentos, com maiores resultados nos manejos Cesp $\left(0,80 \mathrm{Mg} \mathrm{ha}^{-1}\right)$ e Cdap $\left(0,82 \mathrm{Mg} \mathrm{ha}^{-1}\right)$ e menores na Caatinga nativa $\left(0,32 \mathrm{Mg} \mathrm{ha}^{-1}\right)$ e no Craso $(0,34 \mathrm{Mg} \mathrm{ha-1})$. Esta diferenciação não permitiu identificar um padrão de variação que representasse o efeito do corte seletivo sobre os estoques C particulado. No entanto, a similaridade entre Caatinga nativa e Craso sugere que a ausência de intervenção e o manejo mais intensivo favoreceram o acúmulo de $\mathrm{C}$ nessa fração, possivelmente pela manutenção do aporte contínuo de serapilheira na Caatinga nativa e pela grande quantidade de resíduos vegetais deixados nas áreas de corte raso, que estaria estimulando o processo de decomposição microbiana. Em consonância com esta explicação, Batista et al. (2018), estudando a mesma área experimental deste estudo, um ano após o manejo, verificaram correlações significativas entre os estoques de serapilheira e frações oxidáveis do carbono orgânico do solo.

Ao comparar os estoques de C ocluso dos macroagregados com os dos microagregados em cada um dos tratamentos, verificou-se similaridade entre os valores observados para estas frações (Figura 4), representando, em média, $1 \mathrm{Mg} \mathrm{ha}^{-1}$. Por outro lado, houve variação no estoque de $C$ particulado, que foi superior nos macroagregados em relação aos microagregados. Isso demonstra o importante papel da matéria orgânica livre no armazenamento de $\mathrm{C}$ na fração macroagregados (Figura 3).

Maiores quantidades de matéria orgânica particulada nos macroagregados também podem evidenciar a decomposição mais lenta nessa fração, sendo possível que os mesmos fatores ambientais citados anteriormente estejam favorecendo a manutenção do C particulado em frações de maiores tamanhos. De acordo com Bronick e Lal (2005), o tempo de permanência do carbono orgânico do solo e a taxa de decomposição são fatores cruciais na eficácia da agregação. Em outras palavras, o mecanismo que leva ao acúmulo de $\mathrm{C}$ no solo resulta de uma situação ótima entre o turnover de macroagregados e a mineralização do $C$, o que favorece sua oclusão nos macroagregados, com posterior estabilização em microagregados, junto aos minerais do solo (Six et al., 2004). 
Os resultados obtidos neste trabalho revelam que o manejo florestal (MF), independente do tipo de prática adotada, não desencadeou alterações de curto prazo na distribuição e estoques de carbono dos agregados do solo. Estes atributos foram pouco sensíveis em detectar variações ocasionadas pelo MF. Todavia, modificações em outros atributos do solo foram relatadas em demais estudos realizados na mesma área experimental deste trabalho, como por exemplo, na diversidade e abundância da macrofauna (Matos et al., 2019), na comunidade de fungos micorrízicos arbusculares (Pereira et al., 2018) e nas frações oxidáveis do C orgânico do solo (Batista et al., 2018).

\section{CONCLUSÕES}

Em curto prazo, o manejo florestal promove redução dos estoques de carbono orgânico do solo, entretanto não ocasiona alterações na distribuição e estoques de carbono das classes de agregados.

Independente da adoção de manejo florestal na Caatinga, os macroagregados constituem o compartimento com maior capacidade de armazenamento de carbono orgânico.

\section{AGRADECIMENTOS}

Ao Conselho Nacional de Desenvolvimento Científico e Tecnológico - CNPq pela concessão de auxílio financeiro ao projeto.

\section{REFERÊNCIAS}

Andrews, S. S., Karlen, D. L., \& Cambardella, C. A. (2004). The soil management assessment framework: a quantitative soil quality evaluation method. Soil Science Society of America Journal, 68(6), 19451962. http://dx.doi.org/10.2136/sssaj2004.1945.

Araújo, A. O., Mendonça, L. A. R., Lima, M. G. S., Feitosa, J. V., Silva, F. J. A., Ness, R. L. L., Frischkorn, H., Simplício, A. A. F., \& Kerntopf, M. R. (2013). Modificações nas propriedades dos solos de uma área de manejo florestal na chapada do araripe. Revista Brasileira de Ciência do Solo, 37(3), 754-762. http://dx.doi.org/10.1590/S0100-06832013000300022.

Araújo, A. S. F., \& Monteiro, R. T. R. (2007). Indicadores biológicos de qualidade do solo. Bioscience Journal, 23(3), 55-75.

Batista, S. G. M., Barreto-Garcia, P. A. B., Paula, A., Miguel, D. L., \& Batista, W. C. A. (2018). Oxidizable fractions of soil organic carbon in Caatinga forest submitted to different forest managements. Ciência Rural, 48(10), 1-5. http://dx.doi.org/10.1590/0103-8478cr20170708.

Brasil. Ministério do Meio Ambiente - MMA. Secretaria de Biodiversidade e Florestas. Instituto Brasileiro de Meio Ambiente e dos Recursos Naturais Renováveis. (2006). Plano de Manejo Florestal Nacional Contendas do Sincorá (Vol. 1, Informações Gerais sobre a Floresta Nacional). Brasília.

Brasil. (2012, 25 de maio). Lei n 12.651 de 25 de maio de 2012. Dispõe sobre a proteção da vegetação nativa e dá outras providências. Diário Oficial [da] República Federativa do Brasil, Brasília. Recuperado em 23 de outubro de 2017, de http://www.planalto.gov.br/ccivil_03/_ato2011 2014/2012/lei/l12651.htm

Brasil. Ministério do Meio Ambiente - MMA. (2014). Caatinga. Brasília. Recuperado em 17 de junho de 2019, de www.mma.gov.br/biomas/caatinga

Bronick, C. J., \& Lal, R. (2005). Soil structure and management: a review. Geoderma, 124(1-2), 3-22.

http://dx.doi.org/10.1016/j.geoderma.2004.03.005.

Calonego, J. C., Santos, C. H., Tiritan, C. S., \& Cunha Júnior, J. R. (2012). Estoque de carbono e propriedades físicas de solos submetidos a diferentes sistemas de manejo. Revista Caatinga, 25(2), 128-135.

Conen, F., Zerva, A., Arrouays, D., Jolivet, C., Jarvis, P., Grace, J., \& Mencuccini, M. (2004). The carbon balance of forest soils: detectability of changes in soilcarbon stocks in temperate and boreal forests. In H. Griffiths \& P. Jarvis (Eds.), The carbon balance of forest biomes (Vol. 9, pp. 233-247). Southampton, UK: Garland Science/BIOS Scientific Publishers. http://dx.doi.org/10.4324/9780203501344-11. 
Costa Júnior, C., Cássia Piccolo, M., Siqueira Neto, M., Camargo, P. B., Cerri, C. C., \& Bernoux, M. (2011). Carbono Total e $\delta^{13} \mathrm{C}$ em agregados do solo sob vegetação nativa e pastagem no Bioma Cerrado. Revista Brasileira de Ciência do Solo, 35(4), 1241-1252. http://dx.doi.org/10.1590/S010006832011000400017.

Ellert, B. H., \& Bettany, J. R. (1995). Calculation of organic matter and nutrients stored in soils under contrasting management regimes. Canadian Journal of Soil Science, 75(4), 529-538. http://dx.doi.org/10.4141/cjss95-075.

Empresa Brasileira de Pesquisa Agropecuária - EMBRAPA. (2007). Preservação e uso da caatinga (AMC da Agricultura Familiar, No. 16). Brasília: EMBRAPA Informações Tecnológica; Embrapa Semiárido.

Empresa Brasileira de Pesquisa Agropecuária - EMBRAPA. (2017). Manual de métodos de análise de solo (3. ed. rev. e ampl., 573 p.). Brasília: EMBRAPA .

Feller, C., \& Beare, M. H. (1997). Physical control of soil organic matter dynamics in the tropics. Geoderma, 79(1-4), 69-116. http://dx.doi.org/10.1016/S0016-7061(97)00039-6.

Ferreira, F. P., Azevedo, A. C., Dalmolin, R. S. D., \& Girelli, D. (2007). Carbono orgânico, óxidos de ferro e distribuição de agregados em dois solos derivados de basalto no Rio Grande do Sul - Brasil. Ciência Rural, 37(2), 381-388. http://dx.doi.org/10.1590/S0103-84782007000200013.

Gama-Rodrigues, E. F., Ramachandran Nair, P. K., Nair, V. D., Gama-Rodrigues, A. C., Baligar, V. C., \& Machado, R. C. R. (2010). Carbon storage in soil size fractions under two 48 cacao agroforestry systems in Bahia, Brazil. Environmental Management, 45(2), 274-283. PMid:20069301. http://dx.doi.org/10.1007/s00267-009-9420-7.

Instituto Brasileiro de Geografia e Estatística - IBGE. (2012). Manual técnico da vegetação brasileira (2. ed.). Rio de Janeiro: IBGE.

Lima, P. C. F., \& Lima, J. L. S. (1998). Composição florísitica e fitossociologia de uma área de Caatinga em Contendas do Sincorá, Bahia, microrregião homogênea da Chapada Diamantina. Acta Botanica Brasílica, 12(3, Supl. 1), 441-450. http://dx.doi.org/10.1590/S0102-33061998000400013.

Maia, S. M. F., Xavier, F. A. S., Oliveira, T. S., Mendonça, E. S., \& Araújo Filho, J. A. (2008). Nitrogen fractions in a Luvisol under agroforestry and conventional systems in the semi-arid zone of Ceará, Brazil. Revista Brasileira de Ciência do Solo, 32(1), 381-392. http://dx.doi.org/10.1590/S010006832008000100036.

Matos, P. S., Barreto-Garcia, P. A. B., \& Scoriza, N. (2019). Effect of different forest management practices on the soil macrofauna in the arboreal caatinga. Caatinga, 32(3), 1-10. http://dx.doi.org/10.1590/1983-21252019v32n318rc.

Medeiros, F. B., Marcatto, F. S., Silveira, H., \& Nóbrega, M. T. (2018). Avaliação da estabilidade de agregados e a vulnerabilidade à erosão ao longo de uma vertente no município de Araruna, região noroeste do Paraná-Brasil. Caderno de Geografia, 28(55), 845-862. http://dx.doi.org/10.5752/P.23182962.2018v28n55p845-862.

Monroe, P. H. M., Gama-Rodrigues, E. F., Gama-Rodrigues, A. C., \& Marques, J. R. B. (2016). Soil carbon stocks and origin under different cacao agroforestry systems in Southern Bahia, Brasil. Agriculture. Ecossystems and Environment, 221, 99-108. http://dx.doi.org/10.1016/j.agee.2016.01.022.

Pereira, J. E. S., Barreto-Garcia, P. A. B., Scoriza, R. N., Saggin Júnior, O. J., \& Gomes, V. S. (2018). Arbuscular mycorrhizal fungi in soils of arboreal Caatinga submitted to forest management. Agrária, 13(1), 1-6. http://dx.doi.org/10.5039/agraria.v13i1a5497.

Six, J., Bossuyt, H., Degryze, S., \& Denef, K. (2004). A history of research on the link between (micro) aggregates, soil biota, and soil organic matter dynamics. Soil \& Tillage Research, 79(1), 7-31. http://dx.doi.org/10.1016/j.still.2004.03.008.

Souza, A. L., \& Soares, C. P. B. (2013). Florestas nativas: estrutura, dinâmica e manejo. Viçosa: Editora UFV.

Tisdall, J. M., \& Oades, J. M. (1982). Organic matter and water-stable aggregates in soils. Soil Science American Journal, 33(2), 141-163. http://dx.doi.org/10.1111/j.1365-2389.1982.tb01755.x.

Vasconcelos, R. F. B., Cantalice, J. R. B., Oliveira, V. S., Costa, Y. D. J., \& Cavalcante, D. M. (2010). Estabilidade de agregados de um Latossolo Amarelo distrocoeso de tabuleiro costeiro sob diferentes aportes de resíduos orgânicos da cana-de-açúcar. Revista Brasileira de Ciência do Solo, 34(2), 309-316. http://dx.doi.org/10.1590/S0100-06832010000200004.

Virgens, A. P., Barreto-Garcia, P. A. B., Paula, A., Carvalho, F. F., Aragão, M. A., \& Monroe, P. H. M. (2017). Biomassa de espécies florestais em área de Caatinga arbórea. Pesquisa Florestal Brasileira, 37(92), 555-561. http://dx.doi.org/10.4336/2017.pfb.37.92.1465. 
Yeomans, J. C., \& Bremner, J. M. (1988). A rapid and precise method for routine determination of organic carbon in soil. Communications in Soil Science and Plant Analysis, 19(13), 1467-1476. http://dx.doi.org/10.1080/00103628809368027.

Contribuição dos autores: MOS: conceituação, curadoria de dados, análise formal, investigação, escrita primeira redação; PABBG: conceituação, curadoria de dados, metodologia, supervisão, administração do projeto, escrita - revisão e edição; PHMM: curadoria de dados, análise formal, metodologia, recursos, escrita - revisão e edição; AP: metodologia, escrita - revisão e edição. 